\title{
The presence of a primary male caregiver affects children's language skills
}

\author{
Frenette Southwood \\ Department of General Linguistics, Stellenbosch University, 7600 Stellenbosch, South Africa \\ Email: fs@sun.ac.za
}

\begin{abstract}
This study aimed to determine whether the presence or absence of a primary male caregiver influences a child's language skills. A language test was administered to 342 Afrikaans-speaking 4- to 9-year-olds from various socioeconomic backgrounds. The average percentile ranks for the composite language score as well as for the separate language domains of those participants with primary male caregivers was compared to the percentile ranks of those participants without such caregivers. The group with primary male caregivers fared significantly better, implying that the presence of a primary male caregiver has an influence, direct or indirect, on children's language skills.
\end{abstract}

Keywords: primary male caregivers, Afrikaans, child language skills

\section{Introduction}

In South Africa, 39\% of all households (approximately 5,258,000) are female-headed (Statistics South Africa 2008:93). Reported negative effects of an absent or uninvolved father, as is the case in these families, include poor school performance and a greater likelihood of behavioural problems (Black, Dubowitz and Starr 1999; Calderon and Low 1998; Mboya and Nesengani 1999). Children with involved fathers have better cognitive, social and motor competencies than their absent-father peers and are less likely to present with developmental delays (Kelley, Smith, Green, Berndt and Rogers 1998; Shannon, Tamis-LeMonda, London and Cabrera 2002; Yogman, Kindlon and Earls 1995).

It is commonly believed, however, that absent father figures should not affect children's language development to a significant extent, as children are thought to receive their language input primarily from their mothers. This believed primacy of mothers' language input has recently been challenged. Although there is still a dearth of information on fathers' language input - especially in low-income families - evidence is emerging that the language input given by fathers is not negligible (Pancsofar, Vernon-Feagans and The Family Life Project Investigators 2010).

While there are similarities between the language and speech of mothers and those of fathers to their children, there are also clear differences. Regarding the similarities, both parents typically use simplified language - including simple sentence structures, words referring to concrete matters, and precise articulation - exaggerated intonation, a high pitch, a slower rate 
of speech, and high degrees of repetition, amongst others (Klink and Klink 1990; Van de Weijer 1997; also see overview in Papoušek, Papoušek and Haekel 1987:493). In terms of the mean length of their utterances, the proportion of questions, and the diversity of their vocabulary, parents of the two genders use comparable language when conversing with their children (Pancsofar and Vernon-Feagans 2006:580; Rowe, Coker and Pan 2004). Regarding differences, fathers generally talk to their children less frequently than mothers do and make use of shorter conversational turns (Pancsofar and Vernon-Feagans 2006:580). Fathers also ask more questions and make a higher number of explicit clarification requests, and as such present more conversational challenges to their children (Rowe et al. 2004).

Children with involved father figures have been found to have better language skills than their absent-father peers. This has been shown to be the case for African American children from low-income, urban families (if paternal involvement is measured as paternal financial contribution towards the child), as well as for deaf children, where the socio-economic status of the latter group was not specified (Black et al. 1999; Calderon and Low 1998). In a 1978 survey of children from a range of socioeconomic backgrounds, Shinn (1978) found that 16 of the 28 studies reported detrimental effects of father absence on cognitive development (in some studies this included language measurements), nine found no significant effect, and only three found positive or mixed positive and negative effects.

The present study forms part of a larger project on the effect of socioeconomic status ${ }^{1}$ on the language of South African children and aimed to ascertain whether the language skills of Afrikaans-speaking children with absent primary male caregivers are indeed distinguishable from those of children with present primary male caregivers. To date, studies on the effects of the presence/absence of a father figure on language development were mainly conducted in the United States of America, and their findings are not necessarily transferable to South Africa. One reason why caution should be exercised when applying American findings to the South African context is that socioeconomic conditions in South Africa are not necessarily comparable to those in America - for instance, South Africa has a Human Development Index ${ }^{2}$ rating of 0.597 whereas America has one of 0.902 , and a greater proportion of South Africans than Americans is living below the poverty line (Nationmaster 2003-2010; United Nations Development Programme 2010). Socioeconomic status has been shown to influence language development, with poverty-situated children generally having less advanced language skills than their middle-class peers - in this regard, see Flores (2004) who compared homeless, government-housed and university staff members' children; Hart and Risley (1995); Hoff (2003), who measured socioeconomic status in terms of occupation and level of education of the parents; Noble, McCandliss and Farah (2007), who included participants from a range of socioeconomic backgrounds, where the combination of parental education, occupation and income was taken to be a stable indicator of socioeconomic status; and Raizada, Richards, Meltzoff and Kuhl (2008), in whose study the socioeconomic status ranged from so-called blue collar to white collar, as measured by the Hollingshead index (Hollingshead 1975). Because of the different socioeconomic conditions and because language development is sensitive to socioeconomic status, American findings can only be interpreted with caution in the South African context. For this reason, it had to be determined whether the American trend of father-absent children having poor language skills also occurs in South Africa. If it does, effective identification of at-risk children and appropriate preventative intervention need to be considered so that the effect of poor language skills on 
the cognitive activities of school-aged South African children without primary male caregivers can be contained.

\section{Methodology}

\subsection{General procedures}

The study was conducted in eight schools within the Western Cape province as well as in two private daycare centres. Letters were sent to the parents or guardians of all Grade 1 to 3 learners in participating schools and to all children aged four years and older in daycare centres via the classroom teachers or day mothers. Additionally, some participants were sourced through neighbourhood networks of the researcher and her research assistants (five networks in total), and the letters to these parents were delivered by hand. These letters explained the nature of the project and the ethical issues involved (such as the confidentiality of results). The parents were asked to complete a consent form as well as a case history questionnaire (discussed in section 2.4 below) about their child's development and family structure. The questionnaires completed by the consenting parents were scrutinised to ensure that the children met the selection criteria (given in section 2.2 below). Next, those who met the criteria underwent puretone screening following the guidelines of the American SpeechLanguage-Hearing Association (ASHA 1997). Children who passed this screening test then acted as participants, and a language test, the Diagnostic Evaluation of Language Variation (Seymour et al. 2005a; discussed in section 2.3), was administered to each of them.

The raw scores which the participants received on the language test were converted into scaled scores which were in turn converted into percentile ranks. This was done for the test as a whole (rendering a composite score) and also for the domains of syntax, pragmatics and semantics separately. The obtained average percentiles of those participants with involved primary male caregivers were then compared to those without, both for the test as a whole and for each of the above-mentioned domains separately.

\subsection{Participants}

To participate, children had to be mother-tongue speakers of Afrikaans and older than 3 years 11 months but younger than 10 years 0 months, because this is the age range to which the Diagnostic Evaluation of Language Variation (Norm referenced) can be administered. They also had to demonstrate normal development in terms of cognitive, motor and language skills based on the answers their parents gave in the case history questionnaire (discussed below). Children with a history of speech, language or hearing problems and/or prior referral to a speech-language therapist were excluded as participants, as were those with reported visible signs of neurological impairment such as cerebral palsy, brain injury or Attention Deficit Disorder or those who failed the hearing screening.

In total, 342 children between the ages of 4 years 0 months and 9 years 11 months participated (mean age 7 years 6 months; median 7 years 8 months; SD $=1$ year 6 months). These participants were from eight different towns or suburbs and from 15 different schools, daycare centres or neighbourhood groups. Children were selected from urban, peri-urban and rural areas and from both free and fee-paying schools, in an attempt to increase the likelihood of obtaining participants from various socioeconomic backgrounds. In each school, children had to be from a range of classrooms in an attempt to avoid any bias from possible performance grouping within the school. 


\subsection{The language test}

The language test used was the Afrikaans version of the American-developed Diagnostic Evaluation of Language Variation (Seymour et al. 2005a; see Southwood and Van Dulm 2009 and Van Dulm and Southwood 2008 for information on the translation and adaptation of the test for use in the South African context). The American version has been shown to differentiate successfully between children with and without language learning problems, regardless of the dialect of American English which the child speaks. It assesses, amongst others,

(a) syntax, specifically the comprehension of wh-questions and passive constructions, and the correct use of definite and indefinite articles;

(b) pragmatics, specifically the ability of the child to take different communicative roles, to link events together in a narrative, to understand the mental state of characters in a narrative, and to ask appropriate questions in order to obtain the desired information; and

(c) semantics, specifically the ability to fast-map real and nonsense words, to produce verb and preposition contrasts, and to comprehend quantifiers.

The test was administered to each participant individually, and all participants had to perform all tasks for each of the three language domains.

Following the instructions in the Examiner's Manual of the Diagnostic Evaluation of Language Variation (Seymour, Roeper and De Villiers 2005b), scaled scores and percentile ranks were calculated. The Diagnostic Evaluation of Language Variation allows for score adjustment based on parent education level; for the purposes of this study, all scores were left unadjusted. This was done for three reasons:

(a) Because maternal level of education was one of the variables investigated in the larger project, it was not appropriate to adjust the scores based on maternal level of education.

(b) When scores were adjusted, it made a difference to the percentile ranks in only a limited number of cases. (Scores were thus indeed adjusted during the course of the larger project, but the decision was then taken to rather use unadjusted scores.)

(c) The Diagnostic Evaluation of Language Variation has three bands of parental education, namely 12 years or less, 13 to 15 years, and 16 years or more. It was not clear whether the broad band of 0 to 12 years of education would render sufficiently fine distinctions in the South African context.

\subsection{The case-history questionnaire}

The case-history questionnaire was intended to provide

(a) background information on the children in order to determine whether they met the selection criteria,

(b) information about the children's families, and specifically about the caregivers, and

(c) contact information so that a report on the findings could be sent to the parents or guardians.

As such, it consisted of questions (some open-ended and others not) on

(a) the child, including items on medical and general developmental history, language development in particular, hearing status, and access to books and story-tellings;

(b-i) the household, particularly the number of children and adults in the home and their ages, genders and mother-tongues; 
(b-ii) the child's main caregivers, male and female separately: the relation to the child (e.g. father, aunt, guardian, foster parent), whether the person was living in the same house as the child at the time of questionnaire completion, marital status, highest school grade and highest tertiary qualification successfully completed, occupation, and whether the person was employed at the time of completion of the questionnaire. The term "hoof manlike versorger" (= primary male caregiver) was deliberately used instead of "father", in order to ascertain what male person (father, guardian, grandfather, uncle, etc.), if any, acted as the child's father. Note that the male indicated by the person filling out the questionnaire to be the child's primary male caregiver was regarded as such, even if this male did not live in the same house as the child; and

(c) the contact details of the caregiver.

\subsection{Analyses}

Analysis of variance (ANOVA) as well as the Mann-Whitney U-test were performed in order to ascertain whether there is a significant difference between the percentile ranks of the participants with both a primary female and a primary male caregiver and those with only a primary female caregiver (that is, those without any primary male caregiver). The latter test is nonparametric, which makes it suitable for use with the nonhomogenic (in terms of ethnicity, age, parental level of education, geographic status, etc.) population of this study.

\subsection{Ethical considerations}

Permission to conduct the study was obtained from the Western Cape Education Department, from the respective head teachers and from the parents or guardians. Ethical clearance for the study was given by the Research Subcommittee A of Stellenbosch University. The guidelines for ethical research conduct of the Alexander von Humboldt Foundation and the National Research Foundation of South Africa were adhered to throughout the study. Participant identity was protected throughout and all results were treated as confidential. Parents and participants were informed that the child may withdraw from the study at any time without providing reasons for their decision and without suffering any consequences.

\section{Results and discussion}

\subsection{Presence of male caregivers}

Of the 342 participants, all had primary female caregivers. Seventy two percent had a primary male caregiver, $27 \%$ did not, and for another three there were no data available. In most cases (90\%), the primary male caregiver was the father. In 10 cases, the grandfather acted as the primary male caregiver; in seven cases, a guardian; in five, a boyfriend or partner of the primary female caregiver; in two cases, a man specified to be the stepfather (these two children were not siblings); and in one case, a foster father.

\subsection{Language percentile ranks}

Less than half of the participants $(46 \%)$ fell at or above the 16th percentile rank for the language test as a whole. A percentile rank lower than 16 is more than one standard deviation below the norm, and is therefore regarded by clinicians and researchers to be the cut-off value for normal performance on a language test (Botting, Faragher, Simkin, Knox and ContiRamsden 2001:1015). A similar pattern presented itself for the syntax and pragmatics domains, with $52 \%$ and $51 \%$ participants, respectively, falling at or above the 16th percentile. For the semantics domain, participants as a group fared better: (72\%) fell at or above the 16th 
percentile. As these results indicate, between a quarter and a half of the participants show atypical, delayed language development for their age and would therefore be in need of language intervention, despite all participants being regarded as typically developing by their parents. The prevalence of language disorder in otherwise typically developing children is estimated at 7.4\% (Tomblin, Records, Buckwalter, Zhang, Smith and O'Brien 1997), which is lower than in the present study.

\subsection{Language test scores of participants with versus without a primary male caregiver}

The children with a primary male caregiver had significantly higher percentile ranks than those without a primary male caregiver. This was the case for the language test as a whole (Mann-Whitney $p<0.01$ ), the syntax domain (Mann-Whitney $p<0.01$ ), the pragmatics domain (Mann-Whitney $p<0.01$ ), and the semantics domain (Mann-Whitney $p<0.01$ ). Table 1 contains the relevant descriptive statistics.

Table 1. Descriptive statistics for language test scores of participants with versus without a primary male caregiver

\begin{tabular}{|l|l|l|l|l|}
\hline \multicolumn{2}{|l|}{} & \multicolumn{2}{|l|}{$\begin{array}{l}\text { Primary male caregiver } \\
(\mathrm{n}=247)\end{array}$} & \multicolumn{2}{l|}{$\begin{array}{l}\text { No primary male caregiver } \\
(\mathrm{n}=92)\end{array}$} \\
\cline { 2 - 5 } & $\begin{array}{l}\text { Mean percentile } \\
\text { rank }\end{array}$ & $\begin{array}{l}\text { Standard } \\
\text { deviation }\end{array}$ & $\begin{array}{l}\text { Mean percentile } \\
\text { rank }\end{array}$ & $\begin{array}{l}\text { Standard } \\
\text { deviation }\end{array}$ \\
\hline $\begin{array}{l}\text { Overall scaled score } \\
\text { for language test }\end{array}$ & 23.782 & 21.764 & 11.596 & 14.100 \\
\hline $\begin{array}{l}\text { Score for syntax } \\
\text { domain }\end{array}$ & 22.777 & 20.242 & 12.660 & 14.870 \\
\hline $\begin{array}{l}\text { Score for pragmatics } \\
\text { domain }\end{array}$ & 24.666 & 24.432 & 14.130 & 19.234 \\
\hline $\begin{array}{l}\text { Score for semantics } \\
\text { domain }\end{array}$ & 35.532 & 25.631 & 22.277 & 20.485 \\
\hline
\end{tabular}

The education level of their female caregiver has been shown to influence children's language skills (Black et al. 1999; Tomblin et al. 1991). In order to establish whether it is indeed the presence of the primary male caregiver as such that influences the language test scores, and to ensure that the presence of a male caregiver is not merely a function of the female caregiver's education level, ${ }^{3}$ analysis of covariance (ANCOVA) was performed - ANCOVA and F-tests had to be performed as, in this case, there were no suitable nonparametric tests available. After removing the effect of maternal education level, there was still a significant difference between the average percentile ranks of those participants with and those without a primary male caregiver: $F(1,303)=7.171, p<0.01$.

\section{Conclusion}

Children who do not have well-developed language skills upon entering school often struggle academically during the early school years (Snow, Burns and Griffin 1998). The results of this study add to the limited body of knowledge on the language skills of South African children without involved father figures and indicate that fatherless children (where 'father' is defined broadly) are included in this at-risk group: children who grow up without a primary male caregiver have less well-developed language skills (as was previously shown to be the 
case for American children) in all three language domains tested, and such children are thus more likely to experience problems with acquiring reading and writing skills (see Catts, Fey, Zhang and Tomblin 1999).

The social problems of father-absent children are well known. These include a higher risk for substance abuse, mental illness, behavioural problems (including aggressive behaviour), and juvenile delinquency (Cherlin, Chase-Lansdale and McRae 1998; Duncan, Brooks-Gunn and Klebanov 1994:313; Metzler, Noell, Biglan, Ary and Smolkowski 1994; Pearson and Kellam 1995; Rankin and Kern 1994; Vaden-Kiernan, Ialongo). However, the results of this study show that growing up with an absent or infrequently-present father figure affects not only social and psychological well-being, but also language development. Furthermore, ageinappropriate language skills place school-beginners at serious risk for academic failure and premature school exit (Astone and McLanahan 1991; Catts, Fey, Tomblin and Zhang 2002).

This study has several limitations. One thereof is the choice to use a single measure as indicator of socioeconomic status. While maternal level of education is a good predictor of child language skills and thus seems to be an appropriate measure of socioeconomic status, one could also include other measures, such as parent occupation. Another limitation is that the participants were all monolingual speakers of Afrikaans and thus almost exclusively White or so-called Coloured. Because almost no Black children took part in the study, the study population was not fully representative of the South African population and the findings therefore have limited generalisability. The last limitation pertains to the lack of explanation for the obtained results. Although it could be that fathers influence their child's development through "their education or human capital, their possession of skills, knowledge and traits that facilitate achievement" (Pancsofar et al. 2010:451), it is still not entirely clear precisely why children with present father figures should fare better language-wise than children with absent father figures (see also Amato 1998). As such, there is as yet no satisfactory explanation for the findings and conclusion of this study, which is that the positive influence of a primary male caregiver has implications that stretch beyond the financial - children with present primary male caregivers are in better stead to experience academic success due to their better language skills.

\section{Notes}

1. I acknowledge that there are many measures of socioeconomic status, such as income, expenditure, dwelling size, number of breadwinners in the family, number of caregivers in the household, parental level of education, parental occupation and ease of access to infrastructure or basic services. There are also many standardised questionnaires and scales for use in determining socioeconomic status. I decided against using full questionnaires, given that the questionnaires had to be filled out by the caregivers at home without the assistance of the researcher. In my experience, questionnaire completion is a challenging task for some parents (especially those with low levels of literacy), and I was already asking them to complete a full questionnaire on developmental and other household-related matters. For this reason, I opted for a short set of questions on schooling, occupation and employment status rather than a full questionnaire on aspects pertaining to socioeconomic status. Of these, maternal level of education was then taken as the measure of socioeconomic status for the purposes of this study, amongst others because this is the measure used by the language test administered in this study, namely the Diagnostic Evaluation of 
Language Variation (Seymour, Roeper and De Villiers 2005a). As stated by Hoff (2003:1369), "outside of extreme poverty, maternal education appears to be the component of [socioeconomic status] most strongly related to parenting measures", and the latter is thought to influence language acquisition. In choosing maternal level of education as an indicator of socioeconomic status in this study, I am by no means implying that socioeconomic status can under all conditions and in all contexts be gauge by this single measure; rather, in an attempt to simplify matters, that measure of socioeconomic status which had been shown to correlate with child language skills (see Black et al. 1999; Tomblin, Hardy and Hein 1991) was selected for the purposes of this study.

2. The Human Development Index combines indicators of life expectancy at birth, mean years of schooling, expected years of schooling and gross national income per capita into a composite index. A higher value indicates that the country in question is closer to the so-called "maximum goalpost" for a long and healthy life, knowledge, and a decent standard of living.

3. The information given in response to the questionnaire regarding highest school grade successfully completed and highest tertiary qualification obtained was coded based on the number of years of education that the person had: Grades 1 to 12 were coded as 1 to 12 , respectively; being in the process of obtaining a tertiary qualification was coded as 13; a one- or two-year certificate as 14; a three-year diploma as 15; a B-degree or four-year diploma as 16, a first degree which requires more than 4 years of study (such as $\mathrm{MBChB}$ ) or an honours degree as 17 ; a master's degree as 18 ; and a doctoral degree as 19 .

\section{Acknowledgement}

This material is based on work financially supported by the Alexander von Humboldt Foundation. Any opinion, findings, conclusions or recommendations expressed in this material are those of the author and therefore the Alexander von Humboldt Foundation does not accept any liability in regard thereto.

\section{References}

Amato, P.R. 1998. More than money? Men's contributions to their children's lives. In A. Booth and A. C. Crouter (eds). Men in Families: When do They Get Involved? What Difference Does it Make? Mahwah, N.J.; Erlbaum. pp. 241-278.

American Speech-Language-Hearing Association. 1997. Guidelines for Audiologic Screening [Guidelines]. Available online: www.asha.org/policy. Accessed 5 December 2007.

Astone, N.M. and S.S. McLanahan. 1991. Family structure, parental practices and high school completion. American Sociological Review 6: 309-320.

Black, M.M., H. Dubowitz and R.H. Starr, Jr. 1999. African American fathers in low income, urban families: Development, behavior, and home environment. Child Development 70: 967-978.

Botting, N., B. Faragher, Z. Simkin, E. Knox and G. Conti-Ramsden. 2001. Predicting pathways of specific language impairment: What differentiates good and poor outcome? Journal of Child Psychology and Psychiatry 42(8): 1013-1020.

Calderon, R. and S. Low. 1998. Early social-emotional, language, and academic development in children with hearing loss - Families with and without fathers. American Annals of the Deaf 143: 225-234. 
Catts, H., M. Fey, B. Tomblin and X. Zhang. 2002. A longitudinal investigation of reading outcomes in children with language impairments. Journal of Speech, Language, and Hearing Research 45: 1142-1157.

Catts, H., M.E. Fey, X. Zhang and J.B. Tomblin. 1999. Language basis of reading disabilities: Evidence from a longitudinal investigation. Scientific Studies of Reading 3: 331-361.

Cherlin, A.J., P.L. Chase-Lansdale and C. McRae. 1998. Effects of parental divorce on mental health throughout the life course. American Sociological Review 63: 239-249.

Duncan, G.L., J. Brooks-Gunn and P.K. Klebanov. 1994. Economic deprivation and early childhood development. Child Development 65: 296-318.

Flores, R.L. 2004. The effect of poverty on young children's ability to organize everyday events. Journal of Children \& Poverty 10: 99-118.

Hart, B. and T.R. Risley. 1995. Meaningful Differences in the Everyday Experience of Young American Children. Baltimore: Paul H. Brookes.

Hoff, E. 2003. The specificity of environmental influence: Socioeconomic status affects early vocabulary development via maternal speech. Child Development 74: 1368-1378.

Hollingshead, A.B. 1975. Four factor index of social status. New Haven: Yale University, Department of Sociology.

Kelley, M.L., T.S. Smith, A.P. Green, A.E. Berndt and M.C. Rogers. 1998. Importance of fathers' parenting to African-American toddler's social and cognitive development. Infant Behavior and Development 21: 733-744.

Klink, M. and W. Klink. 1990. The influence of father caretaker speech on early language development: A case study. Early Child Development and Care 62(1): 7-22.

Mboya, M.M. and R.I. Nesengani. 1999. Migrant labor in South Africa: A comparative analysis of the academic achievement of father-present and father-absent adolescents. Adolescence 34: 763-767.

Metzler, C.W., J. Noell, A. Biglan, D. Ary and K. Smolkowski. 1994. The social context for risky sexual behavior among adolescents. Behavioral Medicine 17: 419-438.

Nationmaster. 2003-2010. Economy Statistics. Population below poverty line (most recent) by country. Available online at http://www.nationmaster.com/graph/eco_pop_bel_pov_ lin-economy-population-below-poverty-line. Accessed 8 November 2010.

Noble, K.G., B.D. McCandliss and M.J. Farah. 2007. Socioeconomic gradients predict individual differences in neurocognitive abilities. Developmental Science 10: 464-480.

Pancsofar, N. and L. Vernon-Feagans. 2006. Mother and father language input to young children: Contributions to later language development. Journal of Applied Developmental Psychology 27: 571-587.

Pancsofar, N., L. Vernon-Feagans and The Family Life Project Investigators. 2010. Fathers' early contributions to children's language development in families from low-income rural communities. Early Childhood Research Quarterly 25(4): 450-463.

Papoušek, M., H. Papoušek and M. Haekel. 1987. Didactic adjustments in fathers' and mothers' speech to their 3-month-old infants. Journal of Psycholinguistic Research 16(5): 491-516.

Raizada, R.D.S., T.L. Richards, A. Meltzoff and P.K. Kuhl. 2008. Socioeconomic status predicts hemispheric specialisation of the left inferior frontal gyrus in young children. NeuroImage 40: 1392-1401.

Rankin, J.H. and R. Kern. 1994. Parental attachments and delinquency. Criminology 32(4): 495-515.

Rowe, M.L., D. Coker and B.A. Pan. 2004. A comparison of fathers' and mothers' talk to toddlers in low-income families. Social Development 13: 278-291. 
Seymour, H.N., T.W. Roeper and J. de Villiers (with P. de Villiers). 2005a. Diagnostic evaluation of language variation. Norm referenced. San Antonio, TX: PsychCorp, Pearson.

Seymour, H.N., T.W. Roeper and J. de Villiers. 2005b. Diagnostic evaluation of language variation. Examiner's manual. San Antonio, TX: PsychCorp, Pearson.

Shannon, J.D., C.S. Tamis-LeMonda, K. London and N. Cabrera. 2002. Beyond rough and tumble: Low-income fathers' interactions and children's cognitive development at 24 months. Parenting: Science and Practice 2: 77-104.

Shinn, M. 1978. Father absence and children's cognitive development. Psychological Bulletin 85: 295-324.

Snow, C.E., M.S. Burns and P. Griffin. 1998. Preventing reading difficulties in young children. Washington, DC: National Academy Press.

Southwood, F. and O. van Dulm. 2009. Die poeliesman het 'n gun: Die prestasie van Kaapssprekende plattelandse leerders op 'n Afrikaans-medium taaltoets wat dialekneutraal sou wees. LitNet Akademies, 6(2). Available online at http://www.litnet.co.za/cgi-bin/giga.cgi?cmd=cause_dir_news_item\&cause_id=1270\& news_id=72341.

Statistics South Africa. 2008. General Household Survey 2008. Statistical release P0318. Pretoria: Statistics South Africa.

Tomblin, J.B., J.C. Hardy and H.A. Hein. 1991. Predicting poor communication status in preschool children using risk factors present at birth. Journal of Speech, Language, and Hearing Research 34: 1096-1105.

Tomblin, J., N. Records, P. Buckwalter, X. Zhang, E. Smith, and M. O'Brien. 1997. Prevalence of specific language impairment in kindergarten children. Journal of Speech, Language, and Hearing Research 40: 1245-1260.

United Nations Development Programme. 2010. Human Development Report 2010, twentieth anniversary edition. Basingstoke, New York: Palgrave Macmillan.

Vaden-Kiernan, N., N.S. Ialongo, J. Pearson and S. Kellam. 1995. Household family structure and children's aggressive behavior: A longitudinal study of urban elementary school children. Journal of Abnormal Child Psychology 23(5): 553-568.

Van de Weijer, J. 1997. Language input to a prelingual infant. In A. Sorace, C. Heycock and R. Shillcock. (eds.). Proceedings of the GALA'97 Conference on Language Acquisition. Edinburgh: University of Edinburgh. pp. 290-293.

Van Dulm, O. and F. Southwood. 2008. Toward a dialect-neutral Afrikaans-medium child language assessment instrument: Test item development. Language Matters 39: 300315 .

Yogman, M.W., D. Kindlon and F. Earls. 1995. Father involvement and cognitive/ behavioral outcomes of preterm infants. Journal of the American Academy of Child and Adolescent Psychiatry 34(1): 58-66. 